\title{
Introduction of the special edition
}

\author{
Paulo Cesar Mendes Villis \\ University of CEUMA - UNICEUMA
}

The Environment Master started activities in august of the year 2016 with the aims of educate masters with abilities of producing and articulating environmental knowledge aiming at solving current and future problems demanded by society. The program belongs to the Concentration Area Environmental Sciences in CAPES Agency and present two Lines of Research: First area is Planning and Environmental Quality and second area is Health and Environment. Currently fourteen permanent teachers compound the program. In August 2018, with the formation of the First Class, there was a need to publish the results generated, the results of the experimental and theoretical research carried out by the students along with their Masters of the Environment. At this moment, the idea of the elaboration of a Special Edition of the Ciência e Natura Periodic appeared with the purpose of scientific dissemination of the articles resulting from the master's dissertations. The decision by this journal was based on the need for joint publication of high impact publications in "Qualis" periodic belonging to the higher level determined by the CAPES area, thereby leveraging the teaching and learning productions within the "Stricto Sensu" considering that the majority of the articles in the special edition are students of the Masters in Environment and of different undergraduate courses of the University Ceuma - UniCEUMA. In this edition, we will present eleven articles from several related areas, dealing with topics such as allergies, ergonomics, women's health, waste management, noise pollution, microbial bioprospecting and water quality assessment, demonstrating the interdisciplinarity of the program. In the face of all this, it is with great joy and satisfaction that we present the Special Edition of the Masters in the Environment, hoping to contribute to the advancement of research in Brazil. 